\title{
A Scientific Software Verification Library Based on the Method of Manufactured Solutions
}

\author{
David D. Marshull * \\ Califotria Polyterhnic State Liniversity, San Luis Obiapu, CA 9\$407-095\%, USA
}

\begin{abstract}
A software library, ovel1, is being developed in the $\mathrm{C}++$ programming languge that applies the Mothod of Manufactured Solutions (MMS) to a variety of partial differential equation (PDE) problems. This library will allow researchers to utilize MMS as a softwpre verifleation process without developing significant amounts of testing code. The library is split into three components: aolution classes which can be used as manufactured aclutians to PDE prablems; PDE problem clasees which represent apecifle types of PDEs to be solyed (such os linear convection-difusion equation or Poiseon's equation); and post-processing classes that collect the convergence information and can perform varloula analysis techniquev to the canvergence data. In 1rse, any golution class can be used with any PDE problem class and vice versa. This creater a aignificant amount of flexibility in this architecture and allows the end users to customize their MMS tegting procese. In addition, end users are able to dovelop their own solution classes in one of three ways: inkeriting from the solution base clase and implementing thelr own class; providing the functions (as source code to be compiled or as a software library with exported functions) required to evaluate the aolution and ita derivatives; or providing the solution equation as a string to be parsed by the library into a function. This paper will demonstrate a number of features of this library, as wall as demonstrate jta application in a typical use case.
\end{abstract}

\section{Nomenclature}

a Convective wave velocity ir linear convection-difusion problem

S Source term in partial differential equation

$u \quad$ Solution to partial differential equation

Stascripts

$C D \quad$ Convection-Diffusion Term

Trms Marufactured Solntion Terin

Conventions

GCl Grid Convergence Index

MMS Method of Manufactured Solutions

PDE Partial Differential Equationı

Syrredols

$v \quad$ Diflusivity ir tinear convection-difussion problein

\section{Introduction}

COFTWAKL verification is as important concept in sottware development, and jt hes begun to gain in sigDrificance in the ares of softrare development for scientific applications. The distinction between softwarc. verification and software validation that is important to keep in injud. "The AIAA Guide for Verificalion asd Validation of Computationa] Sirsulations" defines ${ }^{1}$ yoftware verification ay "the process of determining that a model implementation accurately represerits the tevetoper's conceptual description of the model and

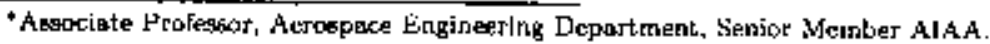


the solntion of the model." In other words, is the cotle solving the equations that it was intended to solve. For software validation, the AJAA guide seys it is the process of detcrmining the degree to which a model is an accurate representation of the real world from the perspective of the intended uses of the model." In other words, is the code modeling the correct equations for the physies of the problesin. This paper will focus un the aspect of software verification.

Roache has authored tro books on the subject of software verification for scientific and engineering software ${ }^{2,}$ is that provide an excellent summary of techniques that can be used to verify soltware. He also presents a thorough description of what information is important w the code developer, who is writing the software, and the expejinentalist, who is yenerating the validation dateset. These two books are excellent references for anyone who is perticjpating in scientific soltware verification and validation.

Tlue book by Knupp and Salori“ provides excellent examples of implementiug softwarc verjication techniques on a wide varicty of problems. They also cover implementation issues sucl as the process of order verification, mestı refinement guidelines for structured and ustruct ured fueshes and the treatment of foust. ary conditions. They also provide excellent gujdance on how to choose a manufactured solution so that it it similar to the expected solution.

Eça and Foekstra have also contributed a number of excellent papers in the field of software verifcation." $3 \cdot 1$ They have focused on the use of the Method of Ylanufactured Solutions, MMS, to perform verification techniques on CFD codes. MMS iu a technique where a solution to a differentiul equation (or sut of differentigl equatione) is astuesed. These call ie cither ordistury or partial dificrential cquations. This asfimed solution is the substituted into the differentije equation(s) end terms are added to the origingl ditferential equation(s) in order to make the esoumed solution an actual solution to the differential equation(6). Section II provides a brief introduction to MMS.

Oberkampf and Roy lave recently produced a book ${ }^{1.5}$ that discusses a wide variety of verificatjon and validation topices as they relate 10 scientific software development. They present a variety of lechniques that cul be used to generate the reference yolution that will be used for comparison in the verification process. In addition to MMS, they also discuss a bariety of ways of obtainirg solutions that are more realistic to the underlying physics of the problem. This can be an importartissuc wher vatidating difjerential cquetions that have a liujted range of applicubility, such as turbulence models in CFD.

\section{Summary of the Method of Manufactured Solutions}

The Method of Manufactured Solutions is a useful method of generating \& reference solution to differentia] equations when an exact solution is not know or is too costly to obtuin. As ar exarnple of how MMS is used, suppose the one-dimensional, linear wave equation witl a source term is the differential equation that we aro trying to perform software verification upon.

$$
\frac{\partial \phi}{\partial t}+c \frac{\partial \phi}{\partial x}-e^{\cdot t}=0
$$

where $\phi$ is the unknowr solution and a is the wave speed. Notice that the source term was moved to the left hand side so that the entire equation was equal to zero. This is so that the MMS source term is eavier to iderstity.

Suppose that we do not know ary exact solution to this pari.iol tifferential equation, PDE, so we are going to assume that the following equation is the solution

$$
\psi_{m m s}=\sin (\alpha x+\beta t)
$$

where $\alpha$ and $\beta$ are arbitrary (non-zero) constants. While $\phi_{\text {mrrs }}$ is not a solution to the original PDE, it is a solution to the following PDE

$$
\begin{aligned}
\frac{\partial \phi}{\partial t}+c \frac{\partial \phi}{\partial t r}-e^{-t} & =S_{\text {mms }} \\
S_{m m r} & =\left\{c \alpha+\beta ; \cos (\alpha r+\beta t)-e^{-t}\right.
\end{aligned}
$$

where $S_{\text {mase }}$ is the sonrce term that necded to be added to the original PDE (1) in order to make (2) a solutjon. The source term is obtained by substituting the assumed solution into the original PDE (1). Any remaining territy on the left, haud side (since we mowerd the original source term to the left hand side as montioned above) are the MMS source term. 
While this paper will rot discuss the concept of boundary conditions as applied to MSS, it is portl. noting that since we have the exact solution: then Dirichlet, Neumann or even more complicated boundary conditions can be applied exactly.

The use of MMS as a boftware verification technique is very promising since it allowg the software developer to compare the computed solution to an exnct sulution. One of the difficulties in itrolementing this is that for each new differential equation solution that is being solved a now MMS source needs to be derived. In addition, it is believed that MMS san be too intrusive jute the soure code since the differential equation being solved needs to be modified in order to make the assumed solution an actual solution. This paper presents the prelininary work on a software library, woll, written in C++ that attempts to audress these two issues and provide a convenient and ensy to use tool for scientific software developert.

\section{Software Architecture}

\section{A. Overview}

There are three main components to ovel1: The Solution Component, the Equation Component and the Post-Processing Component. Each ore is implemented as a separate nanespace. The Solution Component implements a variety of standard mannfactured tolutions. Fach class can calculate its value and its derivatjwe日 for a given input conditions and adheres to the solution interface. Since all solutions imptement lie same interface, chey can be ixherchanged with lithie etlort. The Equalion Component utilizes the solution interface w define a variety of differential equations that can be usod wo perform MMS verification. Currently only a two interfaces have been developed, but more will be implemented in the future. The third component, the Post-Processing Component performs all of the stamdard post-processing that is typically performed for ooftware verification. Currently, this componerit collects the bolutions for the indjvidual solutions that have been performed and calculatee order of accuracy and other isformation that can be displayed to the aser. It is important to remark that these three components only utjlize interfaces from the other components as needed and are not tied to any specific instantisble class. Thus the library user is free to mix specific classes as appropriate to meet ber needs.

\section{B. Solution Component}

The Solution Component is the most fundamental composent in oreli since it repreuents the implementation of the manufactured solutions and exists in the solutyon namespace within the svel1 ramespace. Figure I shows the inheritance hierarchy within this component. The most besic interface is tlue solution interface. This interface specifies how a solution interfaces with the user to provide the solution and the derivatives of the solution. For this interface there are. two methods that represent the interface betwreen the user and the classes. One is the avaluat method that takes a ver.tor that represents the independent parameters and returns the evaluatod solution. This is shown in Liste 37 in the following code. The other method is the avanlate_partial which takes the same vector of indepejdent parameters

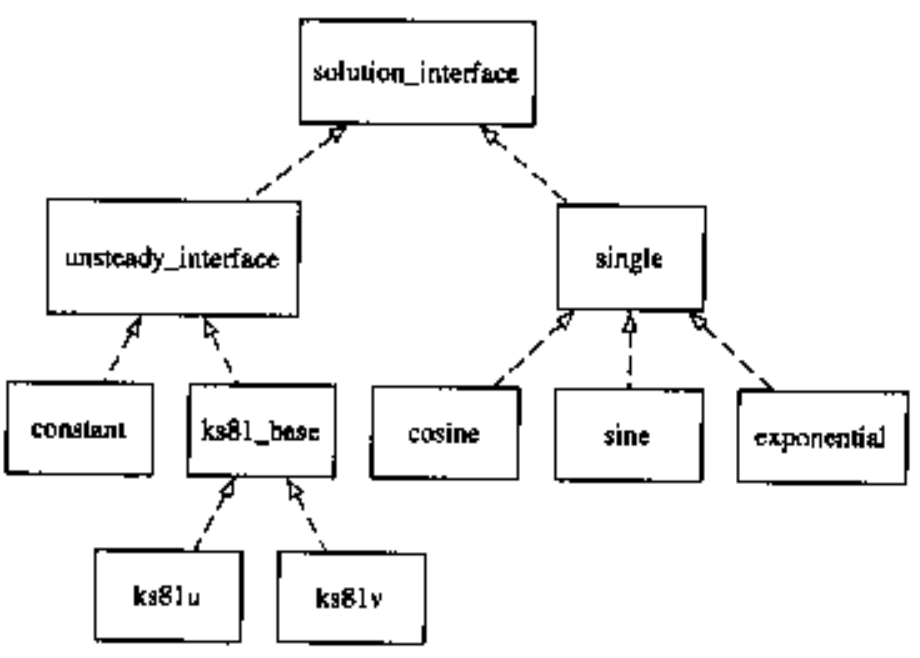

Flyure 1. The Solution Componunt class inherlance hierarchy. and also a vector representing the derivative order(s) desired. For instance, if $\partial / \partial\left(x_{1} x_{2}\right)$ is desired for a solution of three independent variables $\left(x_{1}, x_{2}, x_{3}\right)$, then the vector pessed in would be $[1,1,0]$. The method returns the eva]uated partial derivative. This is shown in Ijine 40 . Notice 
that these methods are abstract since each solution implementation needs to define the functionality of these inethods.

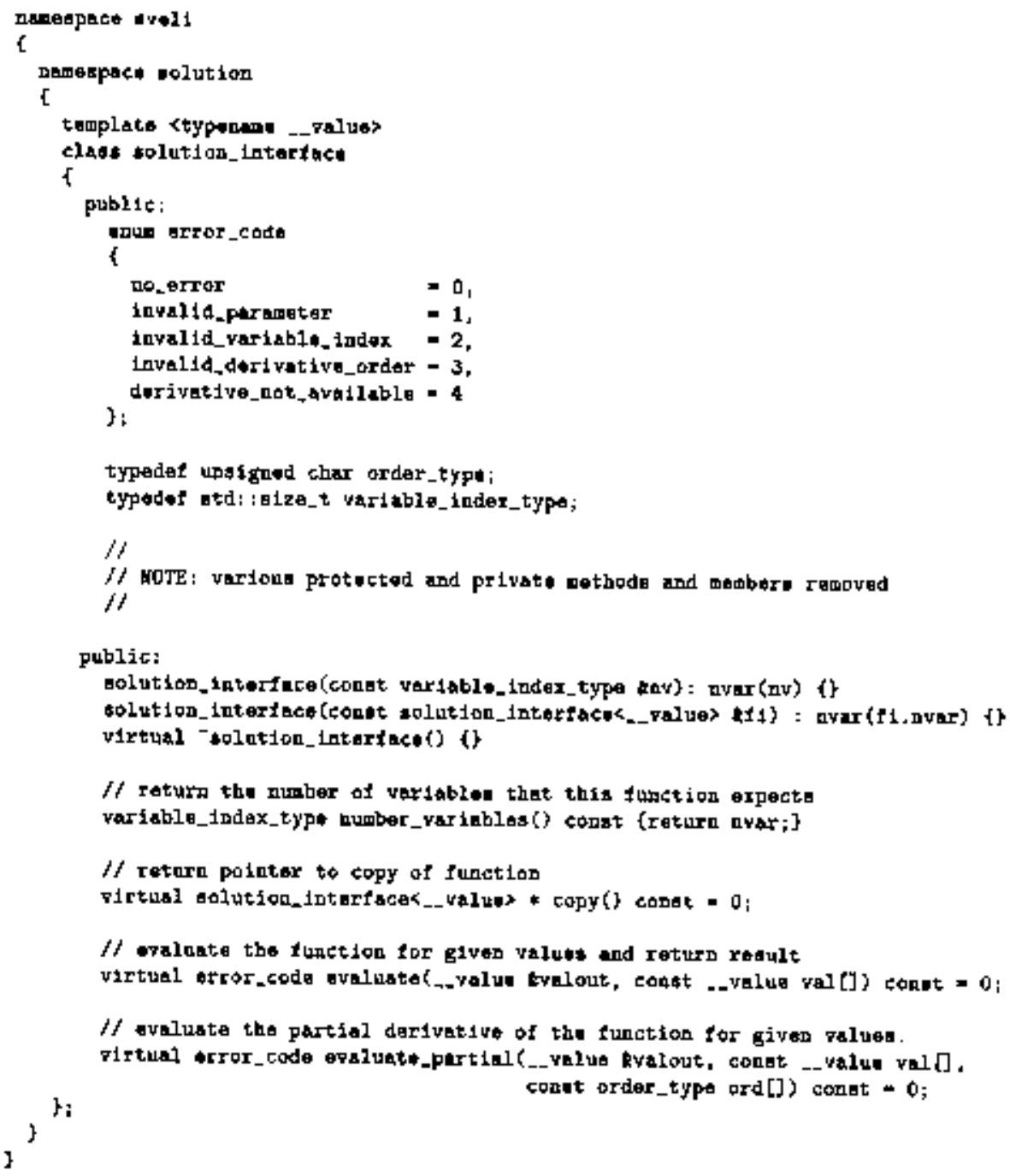

Figure 1 shows an interface that extends the solution interfnce called angle. This interface is a specialization that handles the case where the manufactured solution is a function of une independent parameters. Such examples of this are trigunometric function, and they have been implemented in this library.

Since meny manufactured solutions have an explicit time dependence that is fundarnentally different that the other independent parameters, there is also an unateady solution irterface that is a specialization of the solution interface. Figure 1 ghows this interface and the classes that implement this interfacto. The following code shows the unsteady solution interface with Lisses 14 and 17 slowing the ungtewdy ewalnate and the unsteady evaluate partial derivative methods which are abstract methods that need to be implemented by the spccific unsteady solution classes. Lines 23 and 27 show tlue steady interface versionk of these methods. The unsteady solution interface implements these by persing the irpul vector to the steady versions with the first vector element being the time and the rest of the vector elements bejug the other independent parameters. Thus, to unsteardy interface needs to ro-juplement these, lowever they cas if the wisth.

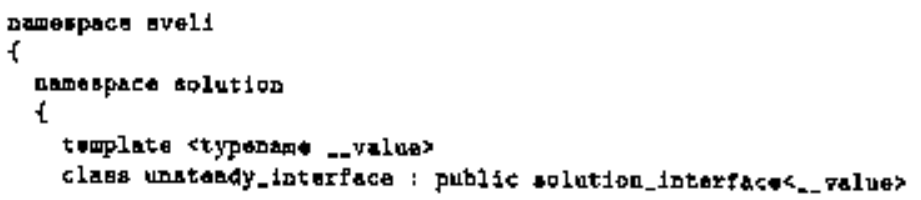

4 of $\mathrm{Jil}$ 


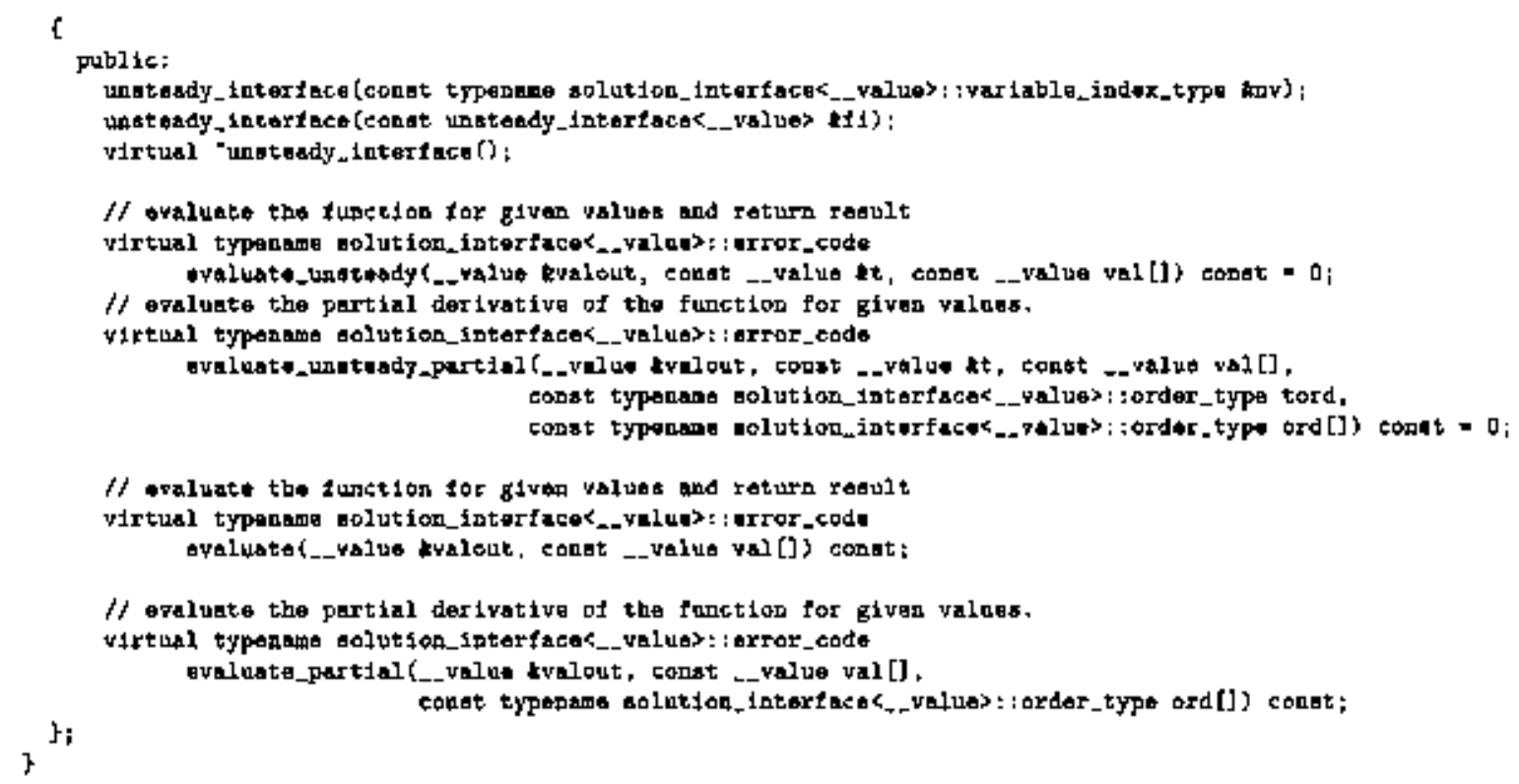

An example implementation of a manufactured solution is one from Knupp and Salari. ${ }^{1}$ They present a manufactured solution of the form

$$
u_{s n m s}(t, \vec{x})=u_{0}[\operatorname{sis}(\vec{x} \cdot \vec{x}+\omega t)+\varepsilon]
$$

that they necd for the validation of the linear, convection-diffusion equation.

With the manufactured oolution chosens, the solution class and the solution derinatives need to be developed. These derivatives are needed for tesks such as bujlding the MMS source term. The evell library has

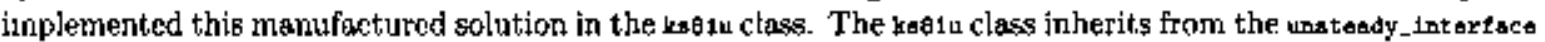
clags since it is a function of time as well as a function of position. It implennents the avalasta_unateady and the avaluata_uneteady_partial methodg. Below showy as example usage of the ksB1u class to evaluate the function:

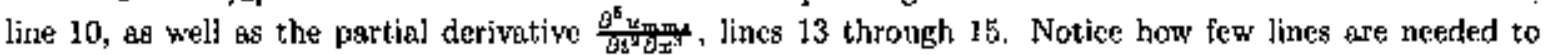
creatc a fully functional mannfactured solution. Lines 1 through 4 are declarations, Line 7 is the initialization of the solution, Line 10 evaluates the solution, Lines 13 and 14 yet the partial derivative order, and Line 15 evaluates the derivative.

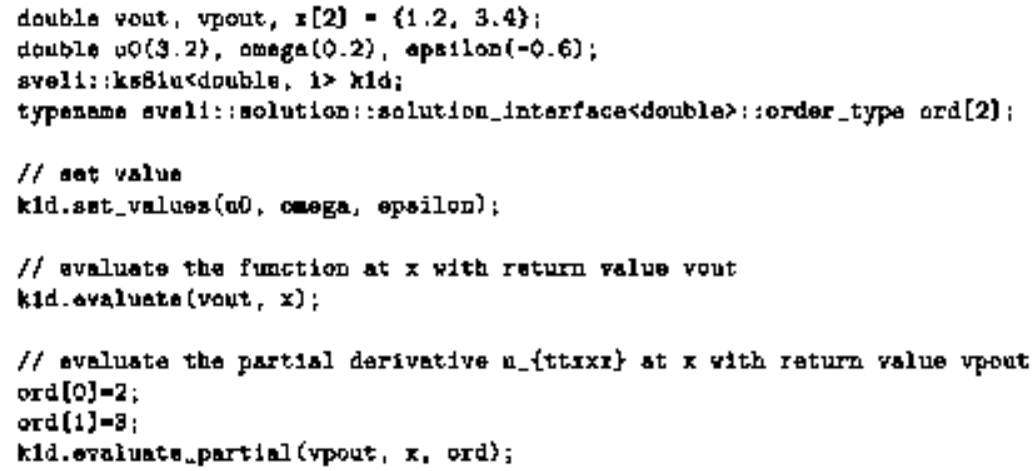

\section{Equation Component}

The Equation Componest represents a particular differential equation to be user in the MMS techrique. It utilizes the solution and unsteady solution interfaces to define the manufactured solution source term. It exists in the oquation namespace within the avel1 namespace. Figure 2 shows the class hierarchy for this component. The pde_problen_base class specifies the basic interface that all equations have. This cominorn 
functionality is spccifyistg of the MMS yolution class and specifying the source term for the differential equation (if it has one). Since there are two types of solution (general and unsteady), there are also two typer of differenlia] equation inter[aces: steady and unsteady. These classes define how the user interacts with the squation class, either with ars explicit time term or not. The code below shows the pde_problow_bast clesss.

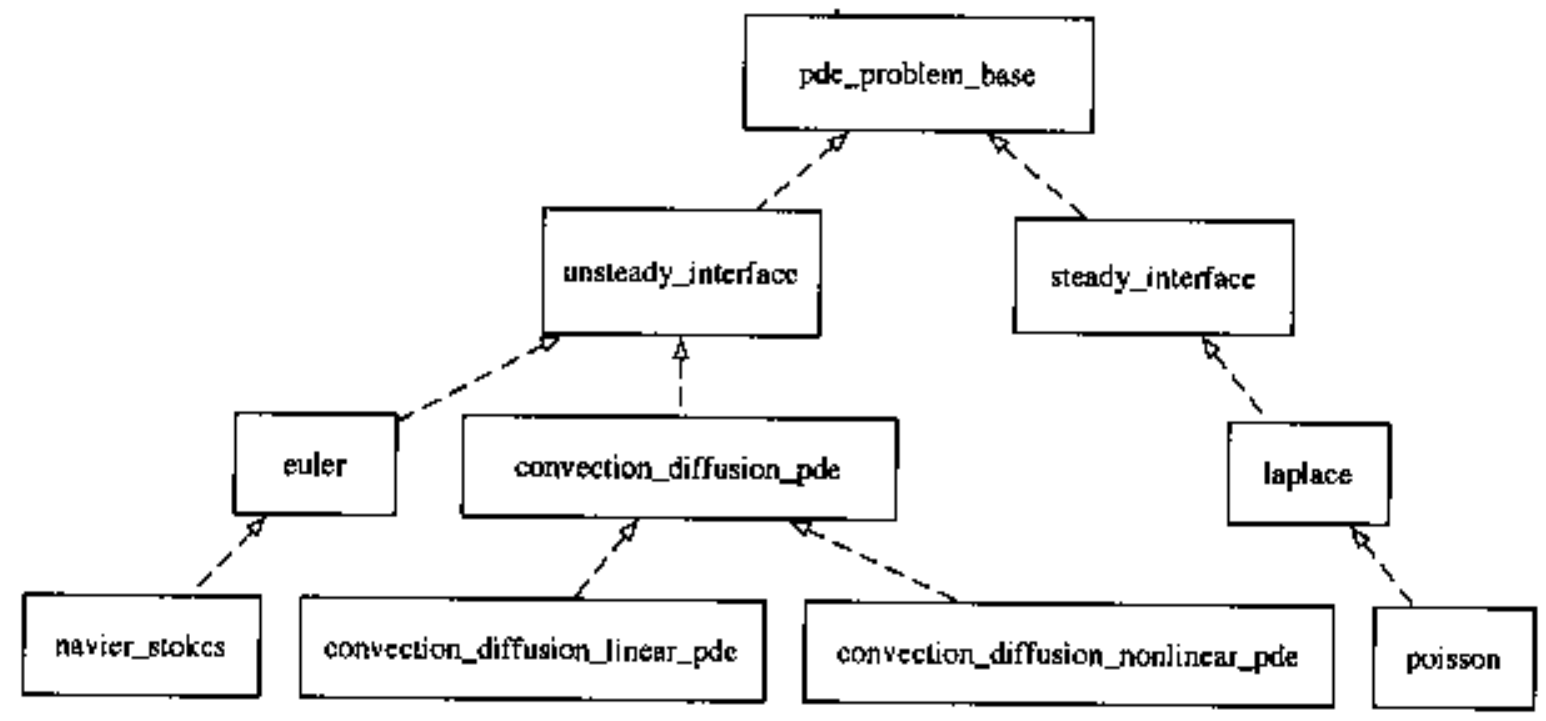

Figure 2. The Equation Component clase inhorttance hlerarchy.

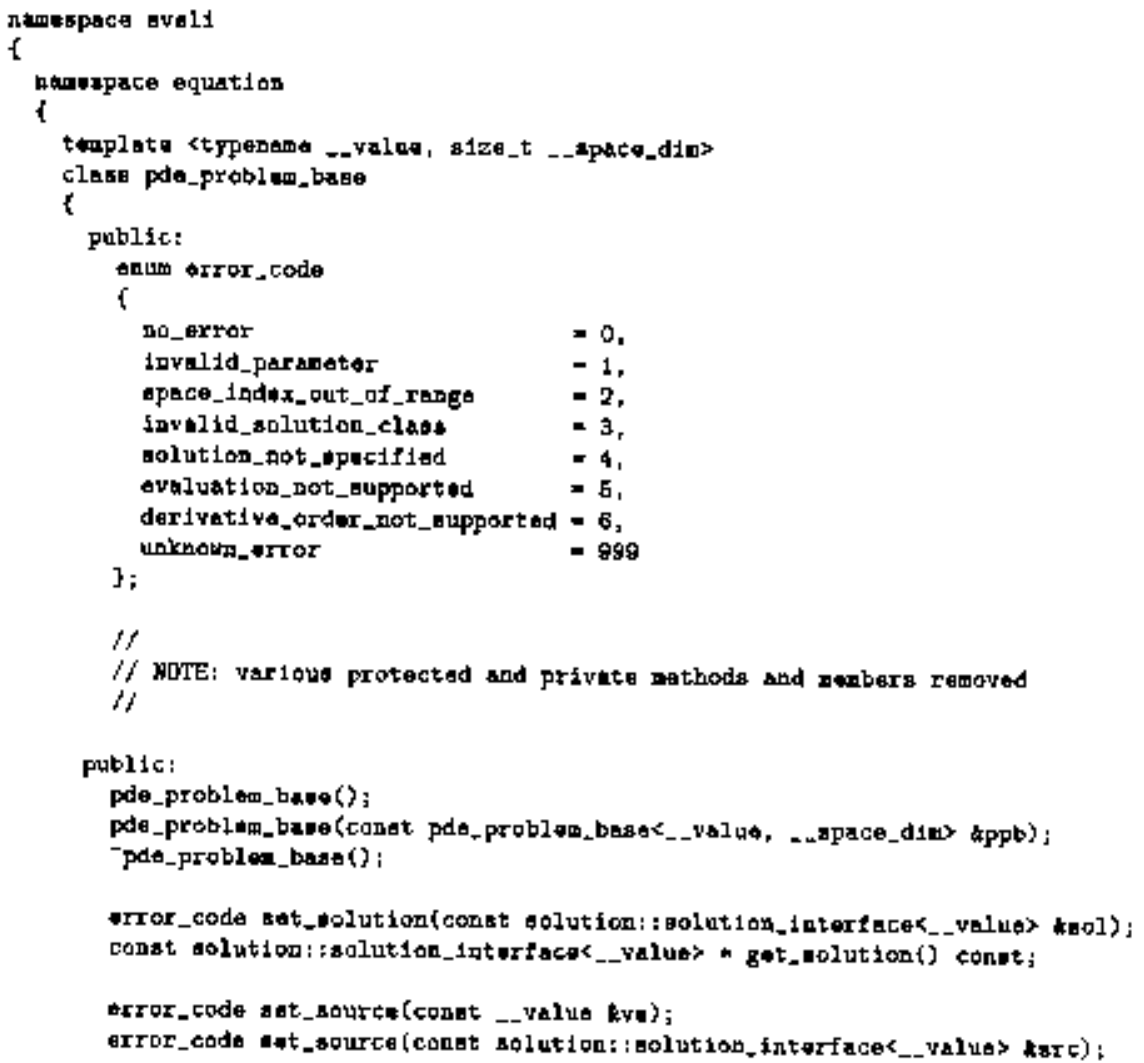




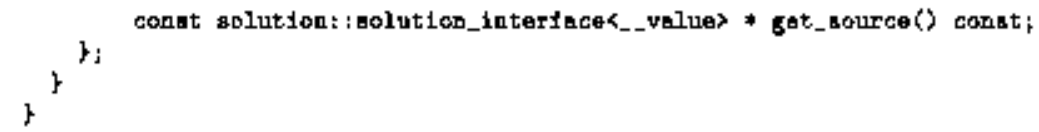

An example cless implemented in this component is the linear convection-diffision problem. The PDE that it represents is

$$
\frac{\partial u}{\partial t}+\vec{a} \cdot \vec{\nabla} u-\nu \nabla^{2} u-S_{C D}=0
$$

where $\overrightarrow{\mathrm{a}}$ is the convective wave speed, $v$ js the diflusivity, and $S_{C} b$ is the source term for the convectiondiffusion problem. Note that each of those terms can be function of space and time.

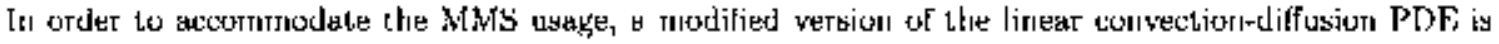
actually solved. This modified equation is

$$
\frac{\partial u}{\partial t}+\dot{a} \cdot \vec{\nabla} u-\nu \nabla^{2} \mathrm{t}-S_{C D}=S_{m เ m}
$$

where $S_{\text {mms }}$ is the manufactured solution source term that is obtained from

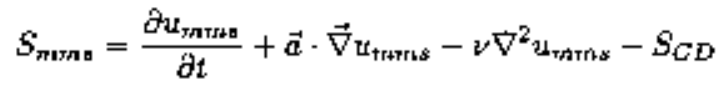

with $u_{m, m}$ representing the specified manufectured solution. Notice that if trmms were an actual solution to Eq. 6, then the manufactured solution source term would be identically zero.

The class that represents thiy is convect1on_diffusion_linas_par. The following code showy the clasy declaration. This class provides the uter the ability to specily the problem parameters such as the diffusivity, the conrective velocity, and the manufactured solution. These can all be specified as constants or as function of time and space via lines 30 through 63 . Lines 17 through 25 are convenience furctions that allow the

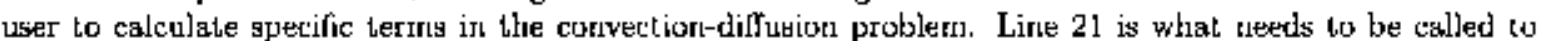
obtain the M1.45 source, eq. 8 . Line 22 is what can be nsed to obtain tho manufoctured solution value. This interface allows the use of spatial and temporal variations for the diffusivity and wave speed by accepting a. function_Interface pointer in the set ruethods, lines 26 and 30.

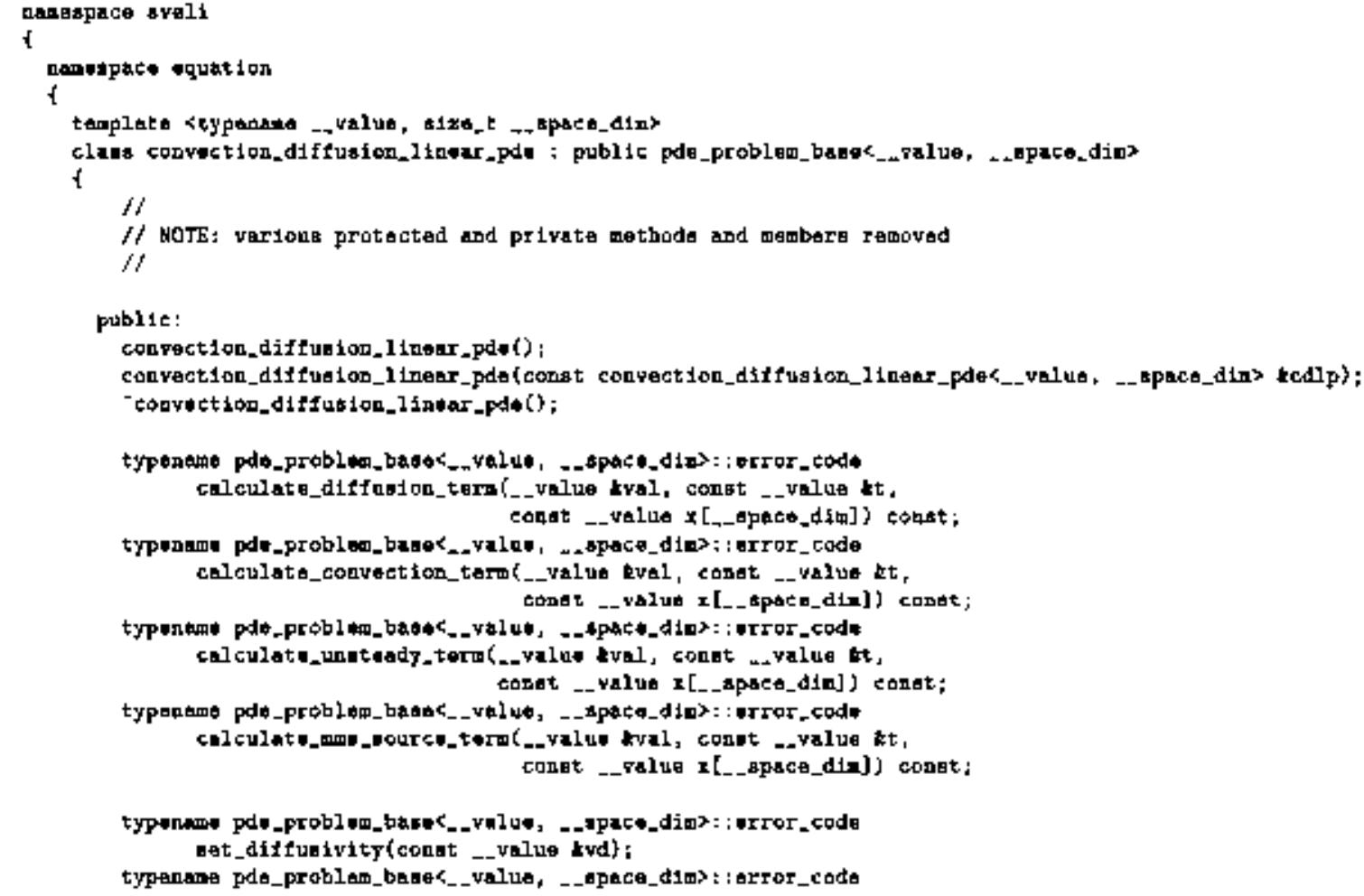




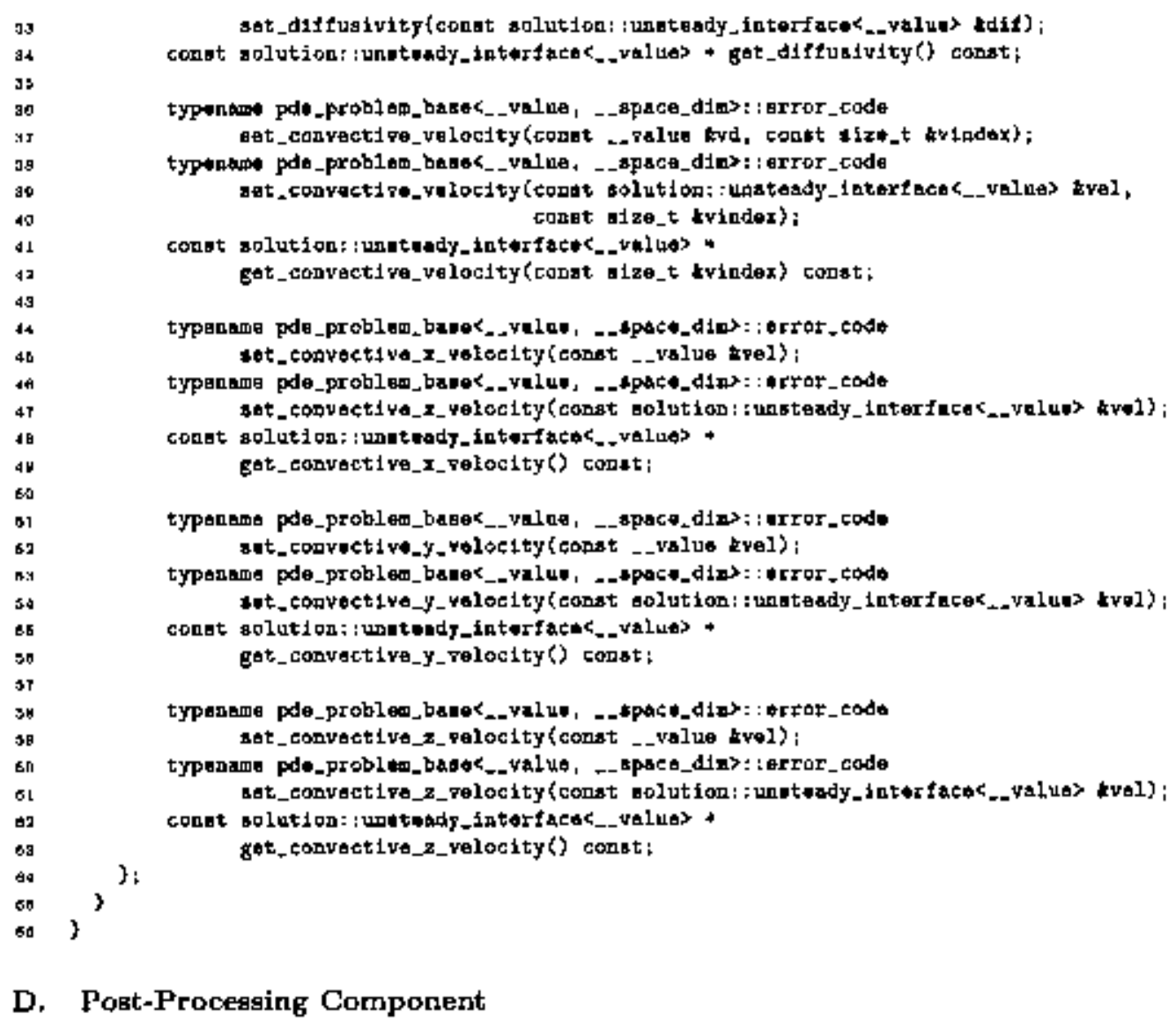

\section{Post-Processing Component}

The Post-Processing Component is the least well developed component in w*11. Currently it has a class to collect the resulty fron one MMS run and a class that stores a collection of results. The resultb collection car then calculate the order of accuracy, the GCI, ${ }^{2}$ tracking the error as reported by the user and other information. These classes exist in the post namespace witlin the oveli nanespace.

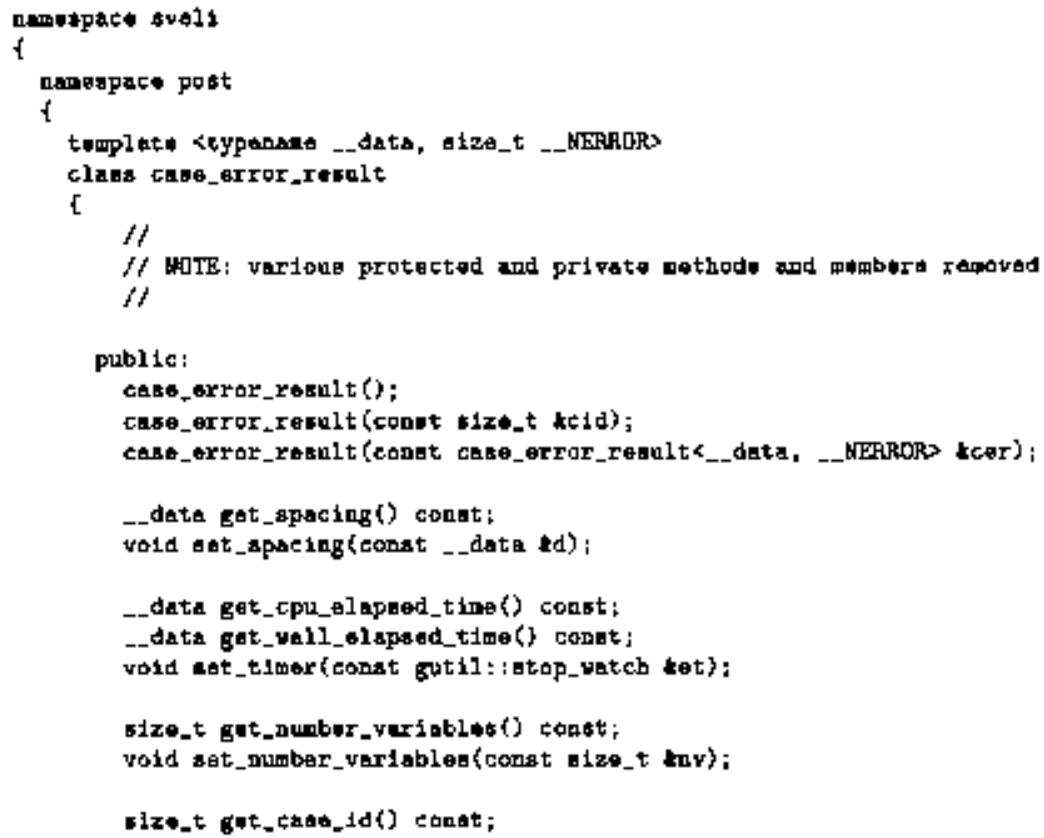




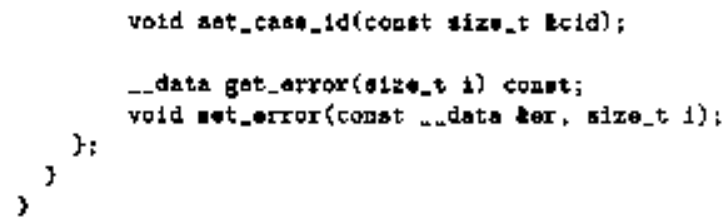

\section{Application of the Linear Convection-Diffusion Equation}

To dcrnonstrate the capabilitieg of avel1, it hab been uked to develop and validate a one-dimensional, linear convection-difussion rquation. The use of this library in the linear convertive-difusion problem required eight. lises of code plus another 10 lines for using the post compostent. Tlie relevaut lines of code are shown below. Limes 6 and 7 create the volution and the PDE problem clases. Iines 10, 1] and 12 injtialize the PDE problem class (this could all have been done in the contructor in line 7, but was not for the sake of clarity). Lines 21 and 22 set the problem's Dirichlet boundary conditions. Lise 25 calculates the MMS source term needed for the problemr solution. In the future, the boundary condition interface will be sdded to the equation interface so that it is clearer to the user how the boundary conditions can be obtained.

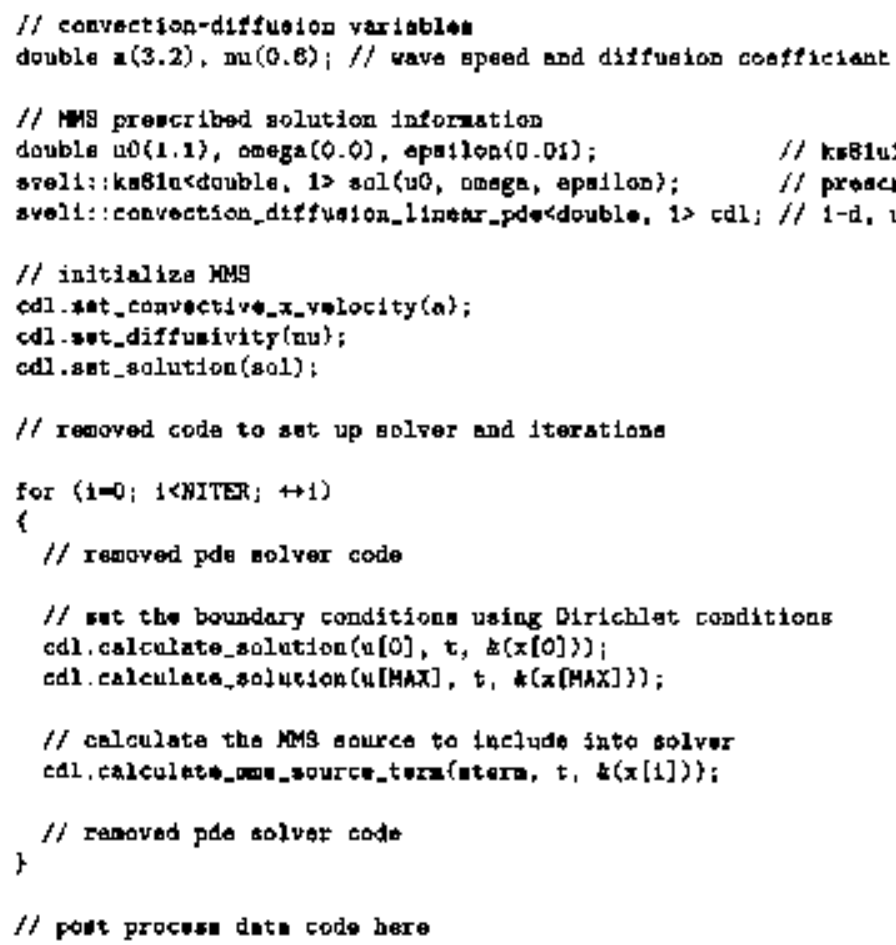

This code was used to solve a linear convection-diffusion problen with $a=3.2, \forall=0.6, u_{0}=1.1$, $\omega=0.0$ (i.e., a steady problerri) ast $\mathrm{E}=0.01$. The problem dornain was $x \in[-0.1,1.2]$, and the prob]em was iterated until the change in the RMS error atad $L_{\mathrm{x}}$ error was less than $1 \times 10^{-6}$. A second order in space, first order in time, fully implicit schente was used to solve l.je probless with the Courant number of 100 . The calculations were performed on a MacBook Pro with a $3.06 \mathrm{GHz}$. Intel Core 2 Duo CPU. The compiler used was gec version 4.5 .

Figure 3 shows the maximurn and the RHS errory for the problem using float, double, and loug clouble (extended precision) data as well as with the donbte-double and quad-double pseudo-primitive types by Hida et al. ${ }^{16,15}$ Since these clases are templated on the data type used for the calculations, changiug the data type is as sirnple as changing the argument to the class instantiations. When tle double double and quad double types were used, the only inodification Ineded was to include the math functions jmplenterted for the double double ard quad doublo libraries since tley should be in the atd namespace and not the default

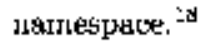


Note that the problem size is reduced beyond the point where roundofi error overwlelms the truncation error of the problets for float, donble and long double. Since the double double and quad double types are even higher precision, their misimums were not reaclied. This wras done to demonstrate the robustness of the library and its ability to bandle any datatype that mimics the primitive datatypes.

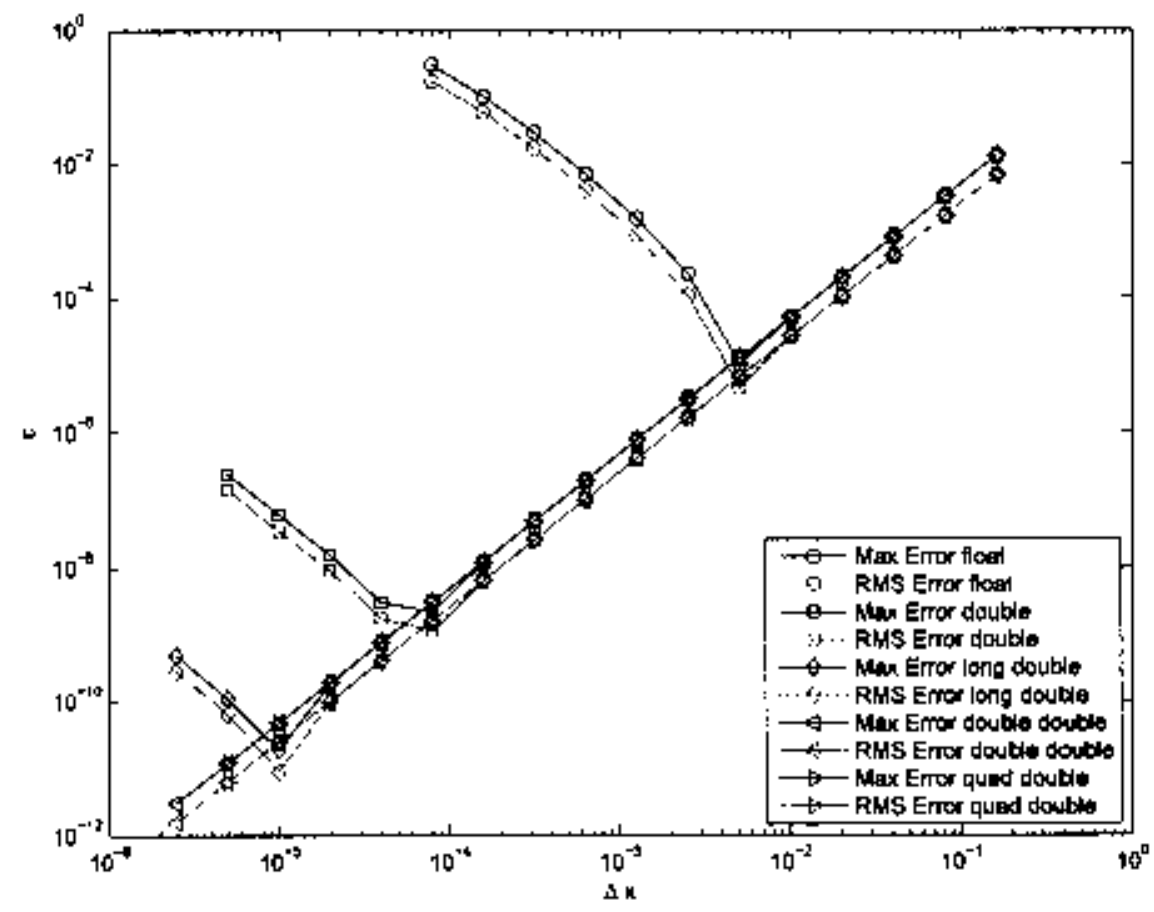

Figure 3. Maximutr uzıd RMS error for the linear convection-difiusion probltuz test chse using a variety of deta types.

Figure 4 shows the resulting CPU timings for the threx difference caseb. 'I hiti informition, along with the inforrstation for Figure '3 was all stored and processed by the library: Notice that there is a slight performanoe penalty for using double (one to two times slower thas foat) or long domble (1.5 to two timnes slewer tlani donble) for the majority of the lest cases, however there is certainly a memory persalty. For doulble double and quad double, the performance penalty is rather severe. Corspared to the long double calculations, the doulle double cases took between seven and eight times as long and the cquad double took between 60 and G4 times as long. Note that sorne of the double and long double cases were not run since they solutions would take multiple days to omplete.

Finally. Taljle 1 shows the calculated spacial order of accuracy lor this problem for a variety of data types. Note that all times show very close to second order convergence behavior until the roundoff error becomes dominant. For the fluat datatype there are not many grid spacing cases before the roundof error dominates. On the other extreme, the roundoff error does not influence the double double or quad donble resulte for any of the grid spacings.

\section{Extending the Applicability of the Library}

There are two immediate wayy that the user can extend this library. One is that the user cas develop their ous solution and use it with an existing PDE problem. They can accomplish this in one of threc ways. They can create their own class that inherits from tho solution_interface class and implement the required methods. Another planned approsch is for the user to use an existing Computer Algebre System (CAS) to differentiate the user's solution equation and have the CAS gencrate furctions for those derivatives. This is the method that is moet conmonly ubed corrently with MMS technique. It is envisioned that these functions would be passed to a class derived from the olution_antorfaco class and can use these functions to returi 


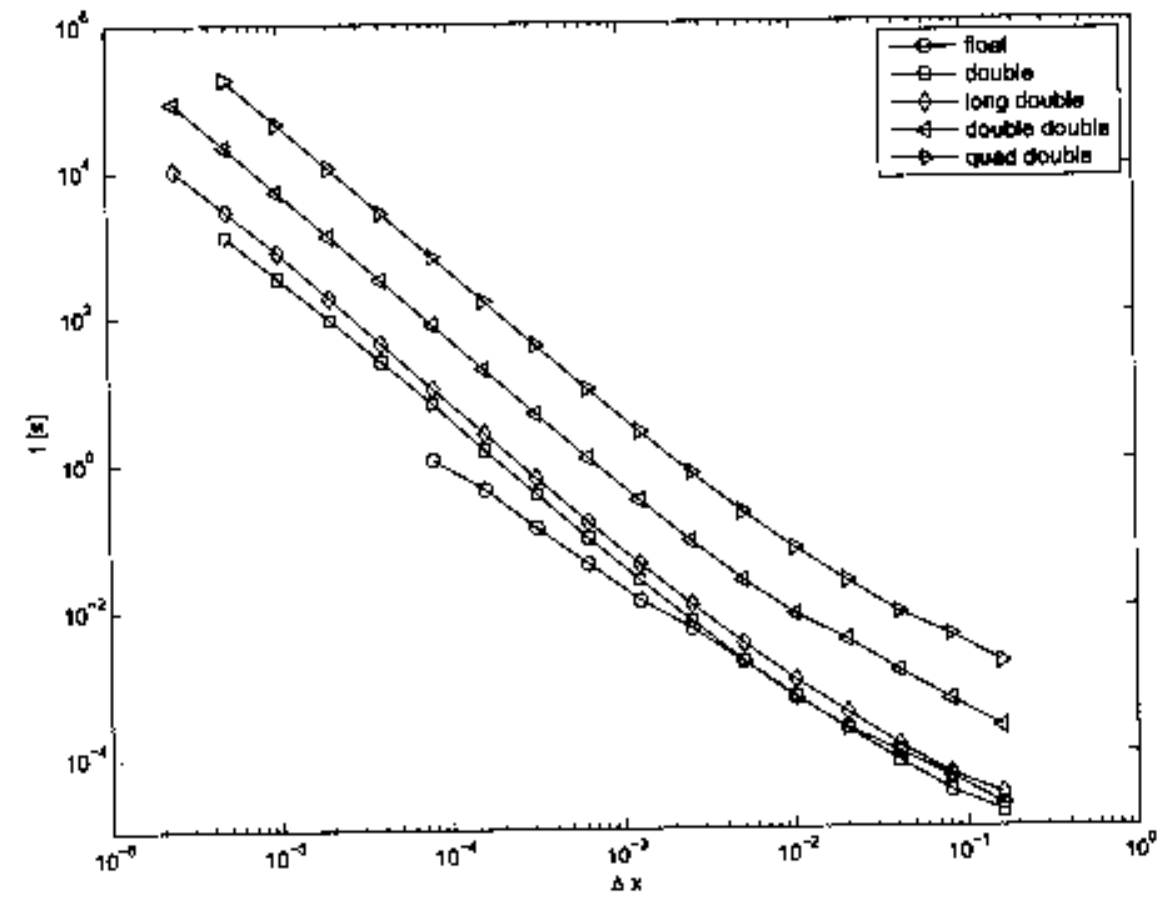

Figure 4. Run-time information for the linear convection-difusion problem teat cage using a variety of dat, typere.

Table 1. The order of accuracy for the linear convection-diffusion problem test case using a varjety of data typer.

\begin{tabular}{|c|c|c|c|c|c|c|c|c|c|c|}
\hline \multirow[b]{2}{*}{ Grid Spacing } & \multicolumn{2}{|c|}{ Float } & \multicolumn{2}{|c|}{ Double } & \multicolumn{2}{|c|}{ Long Double } & \multicolumn{2}{|c|}{ Donble Duuble. } & \multicolumn{2}{|c|}{ Quad Double } \\
\hline & Mex & RMS & $\operatorname{Max}$ & RMS & Max & RMS & Miex & RMS & Max & RMS \\
\hline $8.125 \times 10^{-2}$ & 2.03 & 2.01 & 2.03 & 2.01 & 2.03 & 2.01 & 2.03 & 2.01 & 2.03 & 2.01 \\
\hline $4.063 \times 10^{-2}$ & 2.01 & 1.99 & 2.01 & 1.99 & 2.01 & 1.99 & 2.01 & 1.99 & 2.01 & 1.99 \\
\hline $2.031 \times 10^{-2}$ & 2.01 & 2.00 & 2.00 & 1.99 & 2.00 & 1.99 & 2.00 & 1.99 & 2.00 & 1.99 \\
\hline $1.016 \times 10^{-2}$ & 1.90 & 1.98 & 2.00 & 2.000 & 2.00 & 2.00 & 2.00 & 2.00 & 2.00 & 2.00 \\
\hline $5.078 \times 10^{-3}$ & 2.32 & 2.50 & 2.00 & 2.00 & 2.00 & 2.00 & 2.00 & 2.00 & 2.00 & 2.00 \\
\hline $2.539 \times 10^{-9}$ & -4.50 & -4.55 & 2.00 & 2.00 & 2.00 & 2.00 & 2.00 & 2.00 & 2.00 & 2.00 \\
\hline $1.270 \times 10^{-3}$ & -2.76 & -2.96 & 2.00 & 2.00 & 2.00 & 2.00 & 2.00 & 2.00 & 2.00 & 2.00 \\
\hline $6.348 \times 10^{4}$ & -2.20 & -2.26 & 2.60 & 2.00 & 2.00 & 2.600 & 2.00 & 2.00 & 2.00 & 2.00 \\
\hline $3.174 \times 10^{-4}$ & -2.05 & -2.06 & $2.0 \mathrm{Cr}$ & 2.00 & 2.00 & 2.00 & 2.00 & 2.00 & 2.00 & 2.00 \\
\hline $1.587 \times 10^{-4}$ & -1.80 & -1.80 & 2.02 & 2.02 & 2.00 & 2.00 & 2.00 & 2.00 & 2.00 & 2.00 \\
\hline $7.935 \times 10^{-5}$ & -1.56 & -1.55 & 2.45 & 2.50 & 2.00 & 2.00 & 2.00 & 2.00 & 2.00 & 2.00 \\
\hline $3.967 \times 10^{-5}$ & 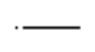 & & -0.46 & -0.65 & 2.00 & 2.00 & 2.00 & 2.00 & 2.00 & 2.60 \\
\hline $1.984 \times 10^{-5}$ & $\cdot-$ & & -2.37 & -2.35 & 2.05 & 2.06 & 2.00 & 2.00 & 2.00 & 2.00 \\
\hline $9.918 \times 10^{-6}$ & $\cdots-$ & & -1.97 & -1.97 & 3.27 & 3.45 & 2.00 & 2.00 & 2.00 & 2.00 \\
\hline $4.959 \times 10^{-8}$ & . - & & -2.00 & -2.00 & -2.52 & -2.85 & 2.00 & 2.00 & 2.00 & 2.00 \\
\hline $2.480 \times 10^{-6}$ & -.. & & - & $\longrightarrow$ & -2.15 & -2.13 & 2.00 & 2.00 & 工 & \\
\hline
\end{tabular}


the requested information. This is intended to be a transition option for those that have existing CAS furctions that they do not want to rewrite $t o$ integrate into this architecture. The third planined option for usces to specify their own solution function via character utrings and have a built-ir CAS convert that into the desired derivatives needed for the PDE problem. This linited functionality CAS is already capable of parsing equations such as: $u 0 *\left(a \ln \left(x^{-} 2+y^{n} 2+z^{n} 2+\right.\right.$ omega*t) $\left.)+\theta p B i l o n\right)$ and creating an equation tree that represents that equation. Once derivatives carn be calculated from this parsed equation then this functionality will be integrated into sveli.

The second way that the user can extend this library by using the solutions without the PDE problem clauses. This mode woruld be most likely used by users who have problems that cannot be repreeented by the existing PDE problem classes but want to take advantage of the automatic differentiation capability of the solution classes. This would require more coding on the end uscr's part, but much less than if they were to attenipt the MMS technique without this library.

\section{Conclusions}

In its current state uvel1 shows a number of the desired features of an MMS library for software verificatiou. The use of MMS to verify a PDE problem with very few lines of code has been thown with the resulty of the test also sllown. The interfaces to the solution classes ant the PDE problern clasees have been well established, and the interface to the post-process functionality is evolving as needs are identified. The interfaces are the most important part to the library usefulness, and as time progresses more solution classes, PDE problem classes and post-processing functiouality will be develuped. In addition wrappers will be developed to allow the use of this library in otjer programminu languages such as C, FORTAN and MATLAB. Also, more differential equation classes will be developed in order to extend the usefulness of this library to a wider variety of users. While there is more to be done, it is believed that aveli represents an excellent first step tuwards a simple scientific ooftware verification library.

\section{References}

1 American Inslisute of Aeronautics artd Astronautics Staff, "Guide for the Vesificaitan and Vulidation of Computalional

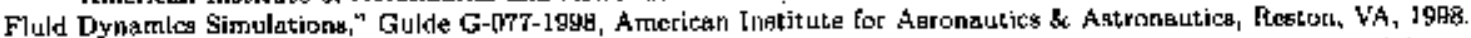

${ }^{2}$ Rasche, P. J, Verbiration and Validation ist Computational Seience tonel Engtineering. Herencad Pulplahera, AJbuquerque; NM, 1998

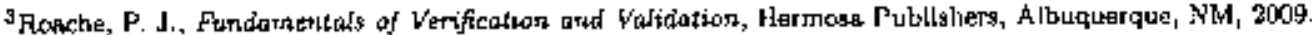

4 Knupp, P. M. tajd Salari, K., Verificatum of Computer Codes ir Comprtintional Science arud Engineering, Discrcte Mathemativa and lts Applications, Chappian \& Hall, 2002.

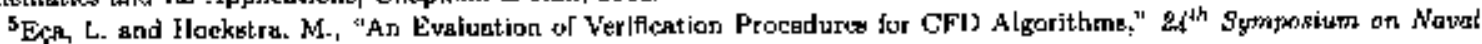
Hydrodimamics, Fukuake, Jepan, July 2002

${ }^{B}$ Eça, L. and Hoakstra, M., "On the Grid Senail|vity of the Whall Boundury Condition of the $k-w$ Turbulence Mordal," Journat of Flusids Engineeritzg, Vol. J26, No. 6, Novemher 2004, Pp. 900-910.

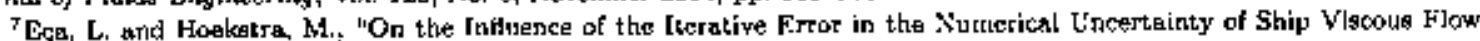

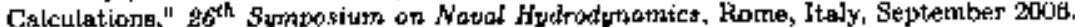

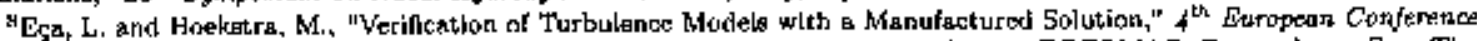
an Comptitational Fluid Dynamics, edited by P. Wezgeling, E. Orate, and J. Péribux, ECCOMfA5, Fgmond an Zac. Thro Netheriand6, September 2006.

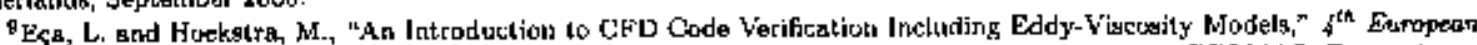

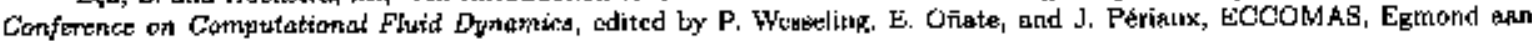
Ze, The Natherlandy, September 2006.

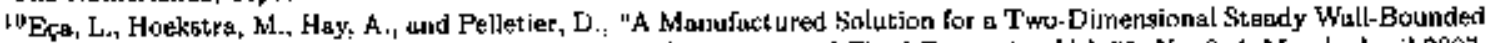

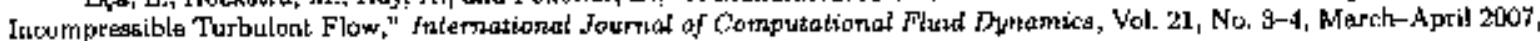
pp. $175-188$.

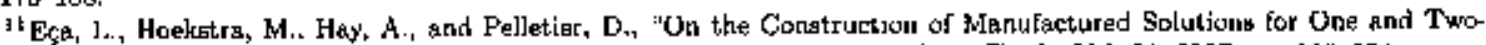

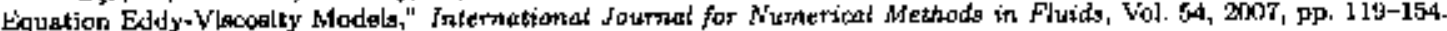

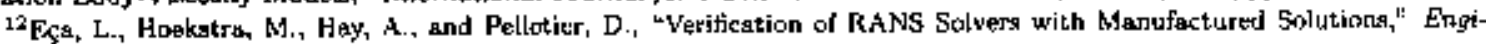
neering with Computers, Vol. 29, 2007, pD. 253-270.

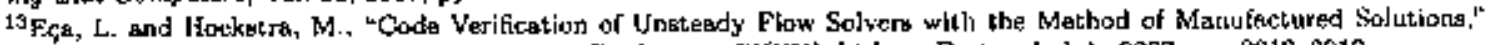
Ith Intertutional Offshore and Folar Engsneering Conference, ISOPE, Lisbon, Portugal, July 2007, pp. 2012-2019.

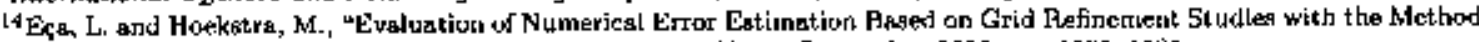

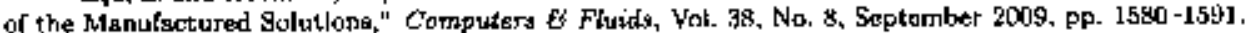

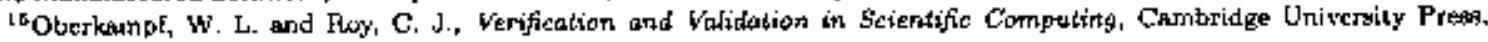
New York, NY, 2010. 


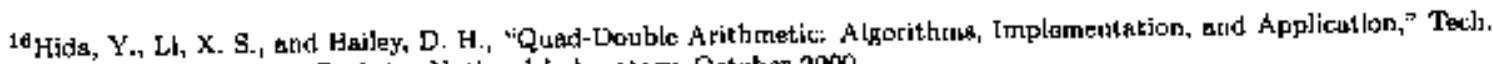
Rep. LBNL 48597, Lawrence Berkeley Nationel Laboratory, October 2000.

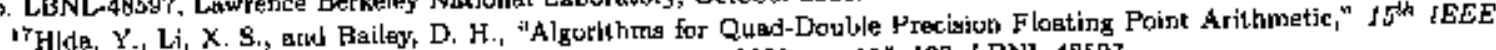
Symposiuan of Computer Arithmelic, IEEE Computer Society, 2001, pp. 155-192, LBNL-48597.

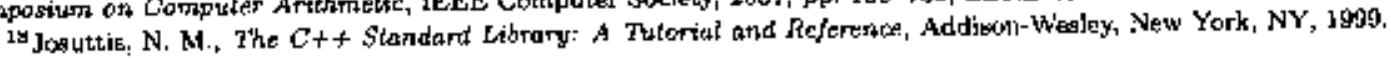

